\title{
Using sea bed roughness as a wave energy dissipater
}

\author{
T. Elgohary ${ }^{1}$, R. Elgohary ${ }^{1} \&$ M. Hagrass ${ }^{2}$ \\ ${ }^{I}$ Department of Civil Engineering (Irrigation and Hydraulic), \\ The Tenth of Ramadan Higher Technological Institute, Egypt \\ ${ }^{2}$ Department of Civil Engineering (Irrigation and Hydraulic), \\ Ain Shams University, Egypt
}

\begin{abstract}
The shoreline is exposed to erosion processes due to water level variation and attacking waves. As a result of erosion processes the shoreline will erode into the sea every year. This phenomenon causes serious damage to all marine structures and coastal resorts. Many practical solutions to protect the shoreline have been found in the past, some have been onshore methods and others have been offshore methods.

Submerged breakwater, shoreline tiles, sea deck, groins, etc., are the different ways of protecting the shoreline. In this study, a practical solution to reduce wave energy was suggested. This solution depends on the concept of increasing the roughness of the sea bed which will then act as a wave energy dissipater to decrease the shoreline erosion process.
\end{abstract}

Keywords: wave energy, energy dissipate, bed roughness.

\section{Introduction}

Theoretical and experimental studies were required to define the suitable bed roughness which is needed to reduce wave energy by deducing the relationships between all the variables involved. The variables involved are bed roughness, sea water depth, wave height, wave frequency time, wavelength, bed effective grain size, sea density and bed particle density as shown in fig. 1, according to Johnson [1], the theoretical part depends on the dimensional analysis of all the variables involved in order to get the mathematical relationship between the different parameters. 


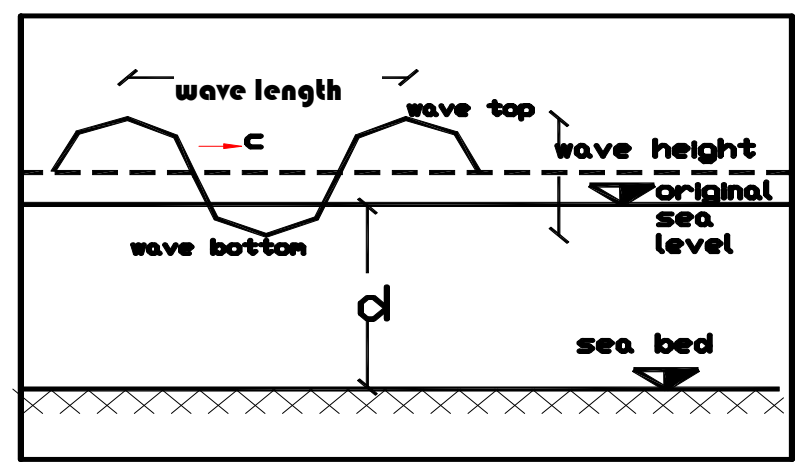

Figure 1: $\quad$ The wave profile.

In the experimental part of the study the exact effect of changing the bed material on wave energy was deduced by a lab model constructed in Ain Shams University Hydraulic Lab (Faculty of Engineering).

The lab model consisted of many different parts. The different parts are an open channel flume equipped with a wave energy creator to simulate the natural conditions in open sea water.

A design chart was deduced by the help of the experimental results analysis. Through this chart we could measure the effect of the bed materials roughness on the wave energy for certain limits.

\section{Study parts}

\subsection{Literature review:}

Wave velocity at any depth of transition zone according to Abido [2]

$$
\mathrm{C}=\text { wave velocity }=\mathrm{C}_{\mathrm{o}} \tan \frac{2 \pi \mathrm{d}}{\mathrm{L}}
$$

At deep zone

$$
\mathrm{C}=\mathrm{C}_{\mathrm{o}}=1.56 \mathrm{~T}_{\mathrm{o}}
$$

where $T_{o}=$ wave period

$\mathrm{C}_{\mathrm{o}}=$ wave velocity at deep zone

$\mathrm{L}=$ wave height $=\mathrm{L}_{\mathrm{o}}$

where

$$
\begin{gathered}
\mathrm{C}_{\mathrm{o}}=\frac{\mathrm{L}_{\mathrm{o}}}{\mathrm{T}_{\mathrm{o}}} \\
\mathrm{L}_{\mathrm{o}}=\mathrm{C}_{\mathrm{o}} \mathrm{T}_{\mathrm{o}}=1.56 \mathrm{~T}_{\mathrm{o}}{ }^{2}
\end{gathered}
$$




\subsection{Theoretical approach}

Buckingham theory has been used to make dimensional analysis of the effective different variables which affect the wave energy dissipation by using bed roughness.

It was found that there are 10 variables which affect the energy dissipation by using bed roughness.

According to the Buckingham theory as mentioned in Khurmi [3]

$$
E=f\left(H, c, L, u, \gamma, \gamma_{s}, d_{50}, d, T\right)
$$

There are 10 variables and $53 \pi$ term repeating variables are $\gamma, \mathrm{d}, \mathrm{C}$. The effective variables are :

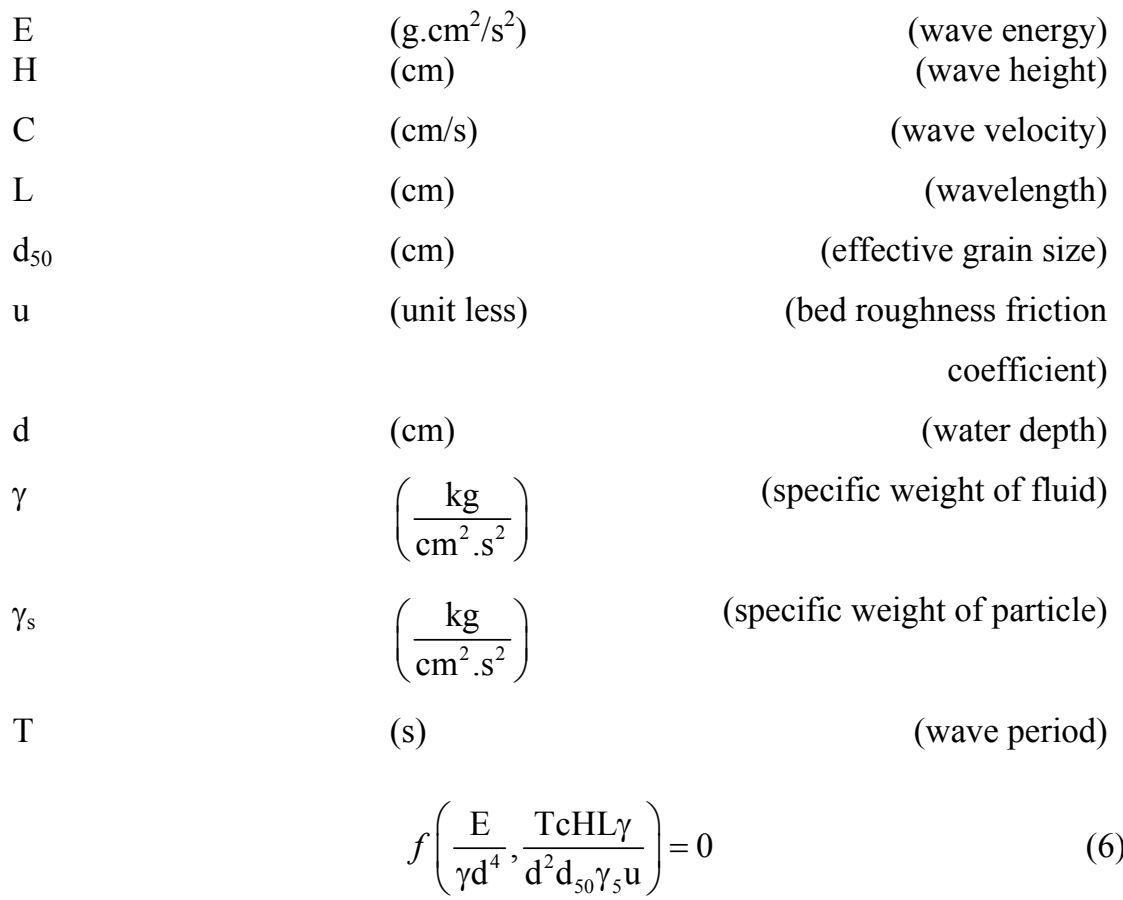

\subsection{Experimental study}

\subsubsection{Experimental procedures}

The experimental study was achieved by using the experimental model as shown in fig 2 which consists of an open channel flume of $30 \mathrm{~cm}$ width and $13.5 \mathrm{~m}$ length. The channel is $35 \mathrm{~cm}$ in height and equipped with a wave energy creator which is connected to the flume .The wave energy creator consists of a steel bar connected to a plate with 12 holes (each hole responsible for a specific wave height).The circular plate of the energy creator is connected to the rotary motor 


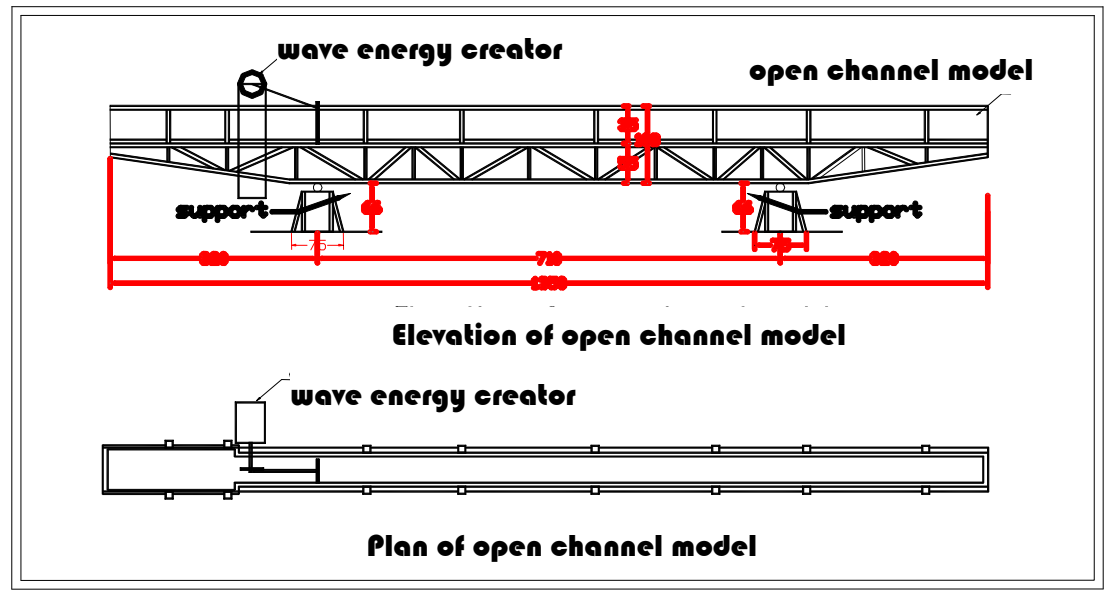

Figure 2: Description of the apparatus.

of a gear box. The channel was filled with water up to $15 \mathrm{~cm}$ in depth for all runs. In each run the bed material was changed and the wave height was also changed. The bed materials were a steel surface at the beginning and particular stones at the end. In each run, the wave height, wave length, frequency time and bed effective grain size were measured. The total number of runs was 12 . The different parts of the experiment model are shown in figures 3 to 5 .

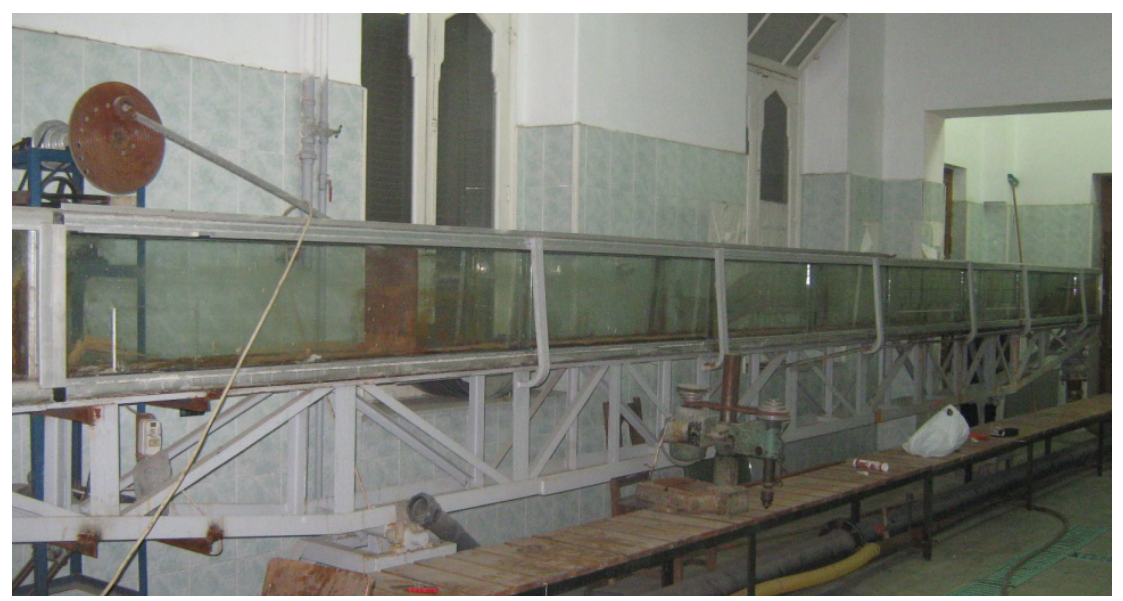

Figure 3: The open channel flume.

The apparatus has been divided into two equal parts lengthways. The steel surface has been used only as bed roughness in the first part and the stones of particular effective grain size of $20 \mathrm{~mm}$ have been used as bed roughness in the 
second part. While the waves were passing along the apparatus from the first part to second part, their behavior changed. The experiments were recorded by video camera. The wave velocity has been calculated by measuring the time which is needed for passing from one particular point to another.

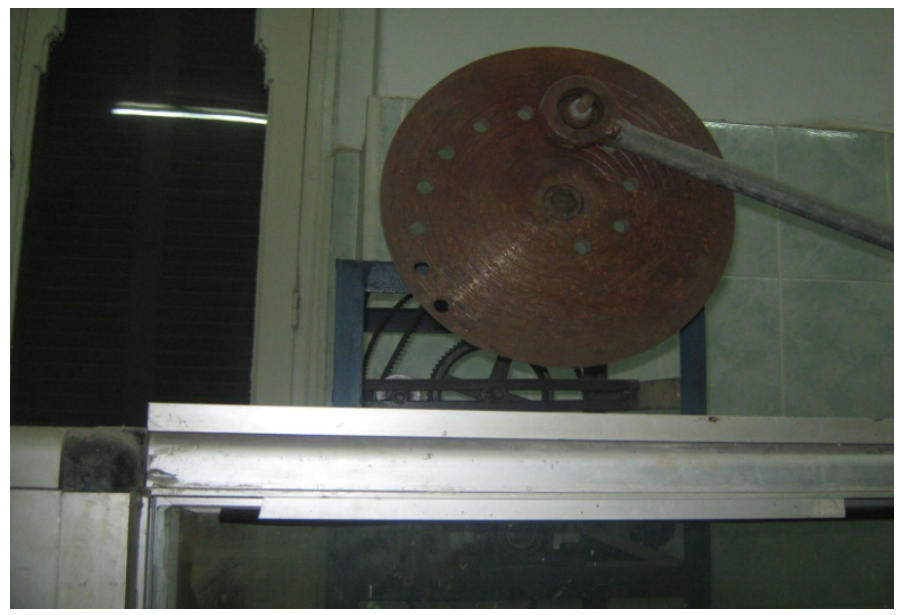

Figure 4: The energy creator.

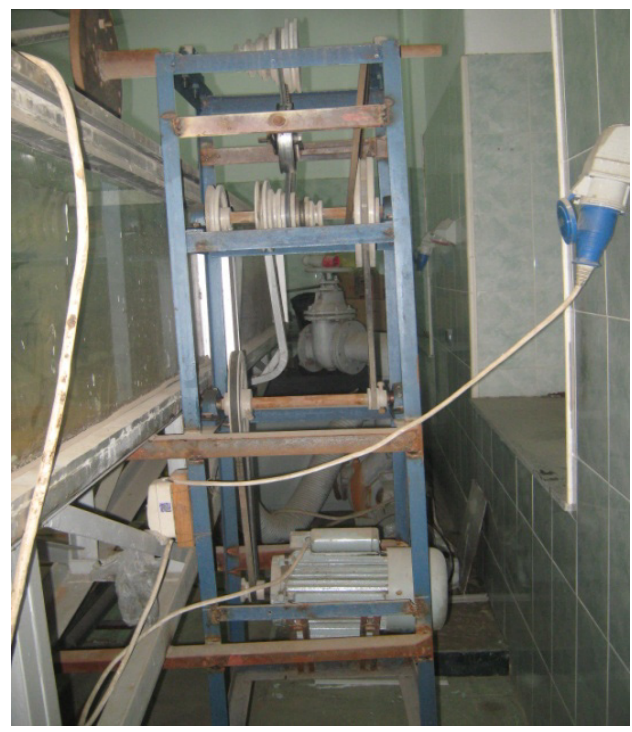

Figure 5: The motor and the gear box. 


\subsubsection{Experimental results}

The experimental results which were obtained directly from the different runs are shown in table 1 and some characteristics of the flow of the experimental runs are arranged in table 2. The 'before' column represents the case when using steel surface only as bed roughness and the 'after' column represents the case when using stones of effective grain size of $20 \mathrm{~mm}$ as bed roughness.

Table 1: $\quad$ Experimental results.

\begin{tabular}{|c|c|c|c|c|c|c|c|c|}
\hline $\begin{array}{c}\text { Run } \\
\text { No }\end{array}$ & $\begin{array}{c}\text { After } \\
(\mathrm{cm})\end{array}$ & $\begin{array}{c}\mathrm{H} \\
\text { After } \\
(\mathrm{cm})\end{array}$ & $\begin{array}{c}\mathrm{T} \\
\text { After } \\
(\mathrm{s})\end{array}$ & $\begin{array}{c}\mathrm{d} 50 \\
(\mathrm{~mm})\end{array}$ & $\begin{array}{c}\mathrm{d} \\
(\mathrm{cm})\end{array}$ & $\begin{array}{c}\mathrm{T} \\
\text { Before } \\
(\mathrm{s})\end{array}$ & $\begin{array}{c}\mathrm{L} \\
\text { Before } \\
(\mathrm{cm})\end{array}$ & $\begin{array}{c}\mathrm{H} \\
\text { Before } \\
(\mathrm{cm})\end{array}$ \\
\hline 1 & 32 & 2.2 & 1.08 & 20 & 13 & 1.02 & 36 & 3 \\
\hline 2 & 35 & 3 & 1.2 & 20 & 11.2 & 1.14 & 38 & 3.5 \\
\hline 3 & 50 & 5.8 & 1.27 & 20 & 17.5 & 1.2 & 60 & 6.4 \\
\hline 4 & 65 & 6.2 & 1.33 & 20 & 16.8 & 1.27 & 75 & 6.6 \\
\hline 5 & 76 & 6.8 & 1.45 & 20 & 16.8 & 1.39 & 90 & 8.0 \\
\hline 6 & 80 & 7.6 & 1.52 & 20 & 16.7 & 1.45 & 104 & 8.6 \\
\hline 7 & 86 & 8.0 & 1.48 & 20 & 16.3 & 1.4 & 110 & 9 \\
\hline 8 & 92 & 9.4 & 1.49 & 20 & 16.3 & 1.46 & 127 & 10.6 \\
\hline 9 & 96 & 10.4 & 1.52 & 20 & 16.2 & 1.48 & 139 & 11.8 \\
\hline 10 & 114 & 10.5 & 1.61 & 20 & 16.2 & 1.52 & 153 & 12.5 \\
\hline 11 & 128 & 10.7 & 1.73 & 20 & 16.0 & 1.56 & 168 & 13.4 \\
\hline 12 & 120 & 11.2 & 1.76 & 20 & 16.8 & 1.60 & 184 & 13.7 \\
\hline
\end{tabular}

Table 2: $\quad$ Flow characteristics.

\begin{tabular}{|c|c|c|c|c|c|}
\hline $\begin{array}{c}\text { Run } \\
\text { No }\end{array}$ & $\begin{array}{c}\text { Fluid } \\
\text { specific } \\
\text { weight } \\
\left(\mathrm{g} / \mathrm{cm}^{2} \mathrm{~s}^{2}\right)\end{array}$ & $\begin{array}{c}\text { Bed } \\
\text { roughness } \\
\text { coefficient } \\
(\mathrm{u}) \\
\text { before }\end{array}$ & $\begin{array}{c}\text { Bed } \\
\text { material } \\
\text { specific } \\
\text { weight } \\
\left(\mathrm{g} / \mathrm{cm}^{2} \cdot \mathrm{s}^{2}\right)\end{array}$ & $\begin{array}{c}\text { Grain } \\
\text { effective } \\
\text { diameter } \\
\mathrm{d}_{50} \\
(\mathrm{~mm})\end{array}$ & $\begin{array}{c}\text { Bed } \\
\text { roughness } \\
\text { coefficient } \\
(\mathrm{u}) \\
\text { after }\end{array}$ \\
\hline 1 & 980 & 0.11 & 2744 & 20 & 0.83 \\
\hline 2 & 980 & 0.11 & 2744 & 20 & 0.83 \\
\hline 3 & 980 & 0.11 & 2744 & 20 & 0.83 \\
\hline 4 & 980 & 0.11 & 2744 & 20 & 0.83 \\
\hline 5 & 980 & 0.11 & 2744 & 20 & 0.83 \\
\hline 6 & 980 & 0.11 & 2744 & 20 & 0.83 \\
\hline 7 & 980 & 0.11 & 2744 & 20 & 0.83 \\
\hline 8 & 980 & 0.11 & 2744 & 20 & 0.83 \\
\hline 9 & 980 & 0.11 & 2744 & 20 & 0.83 \\
\hline 10 & 980 & 0.11 & 2744 & 20 & 0.83 \\
\hline 11 & 980 & 0.11 & 2744 & 20 & 0.83 \\
\hline 12 & 980 & 0.11 & 2744 & 20 & 0.83 \\
\hline
\end{tabular}




\section{Results analysis}

For each run the wave energy before and after the establishing of new bed material were calculated as shown in table 3 . The experiments were recorded by video camera. The wave velocity has been calculated by measuring the time which is needed for passing from one particular point to another for each run.

Table 3: $\quad$ Results analysis.

\begin{tabular}{|c|c|c|c|c|c|c|}
\hline $\begin{array}{c}\text { Run } \\
\text { No }\end{array}$ & $\begin{array}{c}\text { C before } \\
(\mathrm{cm} / \mathrm{s})\end{array}$ & $\begin{array}{c}\mathrm{C} \\
\text { after } \\
(\mathrm{cm} / \mathrm{s})\end{array}$ & $\begin{array}{c}\mathrm{E} \\
\text { before } \\
\left(\mathrm{g} . \mathrm{cm}^{2} / \mathrm{s}^{2}\right)\end{array}$ & $\begin{array}{c}\mathrm{E} \\
\text { after } \\
\left(\mathrm{g} . \mathrm{cm}^{2} / \mathrm{s}^{2}\right.\end{array}$ & $\begin{array}{c}\mathrm{E} / \gamma \mathrm{d}^{4} \\
\text { before }\end{array}$ & $\begin{array}{c}\mathrm{E} / \gamma \mathrm{d}^{4} \\
\text { after }\end{array}$ \\
\hline 1 & 36 & 29.6 & 2.1612 & 1.55 & $7.7215 \mathrm{E}-08$ & $5.52709 \mathrm{E}-08$ \\
\hline 2 & 43 & 29.2 & 2.6934 & 1.94 & $1.7515 \mathrm{E}-07$ & $1.25709 \mathrm{E}-07$ \\
\hline 3 & 50 & 39.4 & 4.4755 & 3.69 & $4.8693 \mathrm{E}-08$ & $4.01685 \mathrm{E}-08$ \\
\hline 4 & 58 & 48.9 & 5.0163 & 3.87 & $6.4257 \mathrm{E}-08$ & $4.95995 \mathrm{E}-08$ \\
\hline 5 & 65 & 52.4 & 6.1556 & 4.8 & $7.8851 \mathrm{E}-08$ & $6.14978 \mathrm{E}-08$ \\
\hline 6 & 72 & 52.6 & 6.9449 & 5.21 & $9.1112 \mathrm{E}-08$ & $6.83723 \mathrm{E}-08$ \\
\hline 7 & 79 & 58.1 & 7.6842 & 5.72 & $1.0579 \mathrm{E}-07$ & $7.8778 \mathrm{E}-08$ \\
\hline 8 & 87 & 61.7 & 9.1617 & 6.64 & $1.3243 \mathrm{E}-07$ & $9.60155 \mathrm{E}-08$ \\
\hline 9 & 94 & 63.2 & 10.408 & 7.24 & $1.542 \mathrm{E}-07$ & $1.07232 \mathrm{E}-07$ \\
\hline 10 & 101 & 70.8 & 11.455 & 7.81 & $1.697 \mathrm{E}-07$ & $1.15671 \mathrm{E}-07$ \\
\hline 11 & 108 & 73.9 & 12.651 & 8.14 & $1.9698 \mathrm{E}-07$ & $1.26684 \mathrm{E}-07$ \\
\hline 12 & 115 & 68.2 & 13.597 & 7.97 & $1.7418 \mathrm{E}-07$ & $1.02132 \mathrm{E}-07$ \\
\hline
\end{tabular}

A chart was plotted in order to represent the wave energy values versus the corresponding effective variables before and after establishing the new bed material, as shown in fig 6.

Fig 6 represents both the results of using a smooth bed and the results of using a rough bed.

As shown in fig 6, case 1 represents the wave energy in the case of using a steel surface as bed roughness and case 2 represents the wave energy in the case of using stones as bed roughness. 


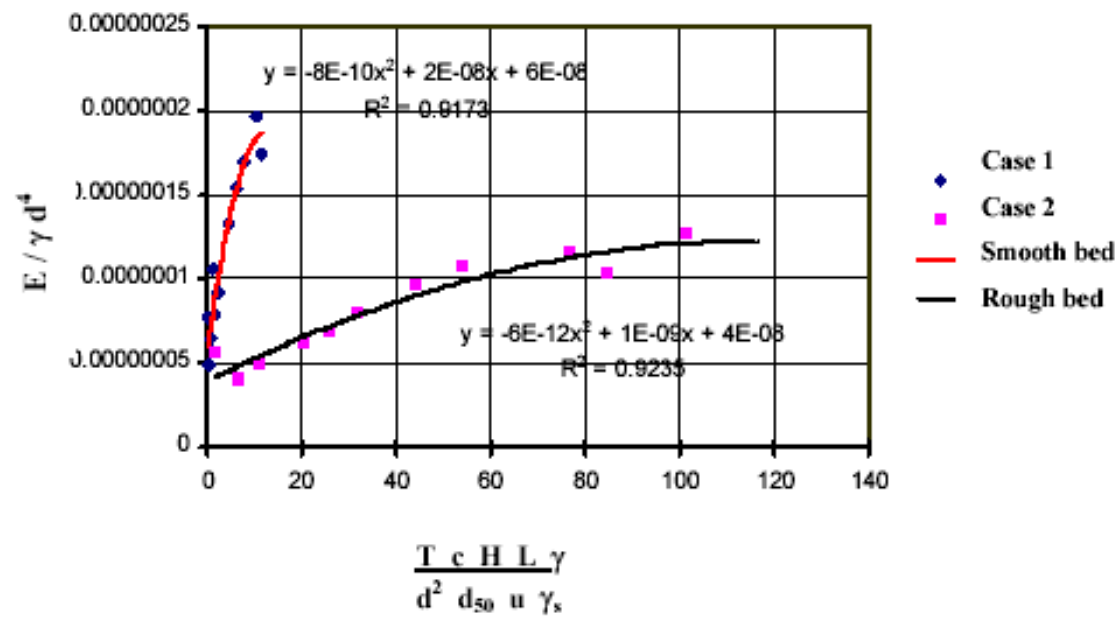

Figure 6: The relationship curve between wave energy and bed roughness.

It was established that the wave energy will decrease when the bed roughness is increased. The friction force between the bed material and the flow is trying to prevent the waves from reaching the beach line with its original total energy. The wave will reach the shoreline with less energy as a result of that and the erosion processes will be decreased on this coastal region.

\section{Conclusions}

Wave energy could be dissipated by using bed material of high roughness coefficient at the sea bottom. The friction force between the bed material of high roughness coefficient and the flow will decelerate the wave velocity. This bed material of high roughness coefficient could be established near the shoreline on the sea bottom in order to decrease the shoreline erosion. This material could be natural or artificial material and must have a high roughness coefficient. This material could be a mixture of different stone types and of different grain sizes. This mixture will be designed especially for a particular region in order to decrease the wave energy to a certain safe limit.

\section{References}

[1] Johnson, D.W (1919): "Shore Processes and Shoreline Development". John Wiley \& Sons, Inc., New York.

[2] Abido, I (2000) “The Harbors Engineering”. Monshaat El maaref Publisher, Alexandria.

[3] Khurmi, R.S (1997) "Hydraulics, Fluid mechanics and hydraulic machines" eleventh edition, S. Chand Publisher, India. 